\title{
7. Creating and implementing large- scale parenting education programs: bridging research, decision making and practice
}

\author{
Linda Neuhauser
}

\section{Introduction}

There is increasing evidence that interventions during pregnancy and early childhood can profoundly affect children's long-term health and wellbeing (Case et al. 2005; Gomby et al. 1995; Heckman 2000; Karoly et al. 1998; McCain and Mustard 2002). For example, parents' knowledge and practices related to health care, bonding with their baby, nutrition, smoking, safety and other factors have a strong influence on children's healthy development (License 2004; NICHD Early Child Care Research Network 2000; Shonkoff and Philips 2000; Shore 1997). Research shows that parenting education is effective, including the more affordable approaches that use mass communication (Neuhauser et al. 2007a). It has been challenging, however, to translate these findings into successful, large-scale and sustainable programs (Green 2001; Simpson 2004; ZervignonHakes 1995).

In fact, research translation is an underlying problem of nearly all educational interventions because of the many obstacles to sharing knowledge persuasively across stakeholder groups, systems and settings (Bammer 2005; Bammer and Smithson 2008; Furler 2008; Green and Glasgow 2006; Innvaer et al. 2002; Neuhauser et al. 2007b; Stokols 2006; Sussman et al. 2006; Tsui 2006). The World Health Organisation (WHO 2004) labels this issue the 'know-do gap'. During the past two decades, there has been intense interest in understanding the reasons for the gap and identifying strategies to bridge it. A key finding is that integrating science for action requires the active involvement of researchers, practitioners and decision makers (Clark and Kelly 2005; Kerner et al. 2005; Lavis et al. 2003; Leischow et al. 2008; Stokols et al. 2008; Tsui 2006; van Kammen et al. 2005, 2006; Zervignon-Hakes 1995). For example, in their systematic review of effective innovations, Greenhalgh et al. (2004) conclude that interpersonal 
networks among stakeholders are necessary to diffuse knowledge. Or, as Lomas (2007:130) comments: 'Human interaction is the engine that drives research into practice.'

The focus on social factors that promote research translation is a notable departure from the traditional technical view of research as a 'product' to be adopted by decision makers and automatically applied by practitioners (Lomas 2000). Studies suggest that a more effective model is one in which stakeholder groups use 'multiple interacting processes' to build consensus around a course of action (Walshe and Rundall 2001) — such as a parenting education programand work together on its implementation and evaluation. It has been difficult, however, to move researchers, decision makers and practitioners from their historically separate roles into close collaboration (WHO 2004). For this reason, there is increased interest in the value of 'knowledge brokers' and supporting institutions to link these stakeholder groups.

This chapter provides an overview of knowledge brokering and how it was critical to developing, testing and extending a parenting education program to benefit more than 500000 families each year. The specific objectives of this chapter are to: 1) discuss issues related to brokering knowledge among researchers, decision makers and practitioners; 2) present a case study of knowledge brokering among these stakeholders to develop a large-scale parenting education program; and 3) suggest strategies to improve knowledge brokering among stakeholders.

\section{Knowledge brokering definitions}

'Knowledge brokering' and 'knowledge sharing' are related to other terms in common use. Tsui (2006:5) defines knowledge sharing as 'the process of exchanging knowledge (skills, experience, and understanding [and I would add: evidence]) among researchers, policymakers, and service providers'. Knowledge brokering implies the added dynamic dimensions of influence and negotiation. Research 'translation' is an extended process describing how research knowledge that is directly or indirectly relevant to health or wellbeing eventually serves the public (adapted from Sussman et al. 2006). Although 'translational research' is sometimes assumed to be a linear process from research to its application, Stokols (2006) describes it as a loop that circulates continuously between research and its application and revision, across multiple actors, sectors and settings.

Dissemination and research dissemination are other common terms that can refer to 'an active and strategically planned process whereby new or existing knowledge, interventions, or practices are spread' (Kiefer et al. 2005:14). King et al. (1998:237) describe dissemination as part of the cycle translating research into action and emphasise that it can be viewed as a 'two-way process that 
exchanges knowledge between researcher and implementer groups'. Knowledge integration is also a contemporary term for knowledge that is viewed as tightly woven within priorities, culture and contexts (Bammer 2005; Best et al. 2007). In such 'systems perspectives', relationships at all levels are keys to access and to integrate knowledge for decision making. Bammer (2005) and Gibson (2003) support the view that interactions between researchers, policymakers and implementers need to go beyond the idea of knowledge exchange and influence to 'transform' knowledge so that is invested with meaning and power that binds parties to new thinking and action.

In this chapter, I use 'knowledge brokering' to reflect a more comprehensive meaning of the above terms: 'a cyclical interaction of stakeholders to integrate and transform their experiences and evidence across time and place in pursuit of a common goal.'

\section{Challenges to brokering knowledge}

Increasingly, we are learning about key barriers to knowledge brokering. Bammer (2005), Lomas (2000, 2007), Kerner et al. (2005), King et al. (1998), Leischow et al. (2008), Tsui (2006) and others point out the differing incentives and systems in which researchers, decision makers and practitioners operate. Researchers, for example, are motivated more to conduct basic, rather than applied studies and to communicate results via academic journals - a lengthy process and one that often restricts information for other stakeholders. Conversely, decision makers often need timely, well-digested information to make decisions that fit within yearly budgets or political terms. Practitioners might prefer to draw on their own experiences and might have inadequate access to understandable research findings or limited power to change practices within their institutions. For all parties, knowledge sharing requires additional time, funding, sensitivity and persistence to work across these diverse cultures. Given such obstacles, it is not surprising that the aforementioned scholars also point out that stakeholder groups often lack the strong relationships and participatory processes that are at the heart of successful knowledge brokering.

\section{Leveraging theoretical guidance and empirical evidence}

Many disciplines offer conceptual guidance to improve knowledge brokering. For example, social ecology (Stokols 2000) and systems models (Lenaway et al. 2006) emphasise the interdependence among sectors and settings and their mutual 
influence. Participatory/action research frameworks (Israel et al. 1998; Minkler and Wallerstein 2003) suggest processes to link stakeholders and organisations for better research and application. Diffusion of innovations (Greenhalgh et al. 2004; Rogers 1982) and other communication models (Neuhauser and Kreps 2003) describe phases of change as knowledge is integrated into action. There are newer models that link multiple frameworks, such as Bammer's (2005) integration and implementation science model and Stokols' (2006) transdisciplinary action research.

Little empirical evidence exists about the effectiveness of specific knowledgebrokering processes (Abrams 2006; Kerner et al. 2005; Tsui 2006). Observations of collaborative work across sectors and disciplines, however, suggest a number of potentially important factors, including (Bammer 2005; Bielak et al. 2008; Ferlie et al. 2000; Greenhalgh et al. 2004; Hutchings et al. 2006; Lomas 2000, 2007; Sussman et al. 2006; van Kammen et al. 2005; WHO 2004)

- leadership and negotiation skills to work across sectors

- multi-institutional support for collaborative work

- strong participatory processes

- respect for others' models and methods

- development of a common language

- regular face-to-face meetings

- verbal and non-verbal communication skills

- motivation and incentives to participate

- expertise in problem-based research and practice

- adequate funding and time.

Among the most innovative and promising efforts are those that explicitly train knowledge brokers and create systems to support their work. For example, the Canadian Health Services Research Foundation (2003) defines its role as a 'knowledge-brokering agency'. It trains health researchers in knowledgebrokering skills, requires that each research project has a decision maker as a co-investigator and that practitioners who are to implement research results coproduce research summaries. The Netherlands Organization for Health Research and Development (ZonMw) pioneers knowledge transfer by organising meetings between researchers, practitioners and decision makers, gathering information about innovation processes and by assigning an 'implementation advisor' to each research program (van Kammen et al. 2005). 
Clearly, knowledge brokering is critical to foster successful collaboration between researchers, practitioners and decision makers, which is needed for better societal interventions. How might we apply what has been learned about knowledge brokering to improve parenting education? Below, I describe the knowledge-brokering strategies used in a large-scale program in the United States.

\section{Knowledge brokering in the First 5 California program}

In 1998, the residents of the US state of California approved a tobacco tax to establish a commission that would support programs to benefit young children and their parents. The resulting First 5 California Children and Families Commission ('First 5'; <http://www.ccfc.ca.gov/>) decided to create a Kit for New Parents that would be distributed free of charge to approximately 500000 expectant and new parents every year. This ambitious effort required designing a kit that would be low cost and include key evidenced-based information about pregnancy and caring for young children, and linkages to important health, parenting, social and other services state-wide. The kit had to be engaging and easy to use for diverse parents and practical for service providers to distribute. It also needed to be accepted by policymakers and service providers in each of the state's 58 counties (each with its own local government and health and social systems). Finally, to determine whether the kit initiative would be approved as a long-term investment, policymakers would need evidence of the kit's positive impact on parents and providers.

During 2000, a multimedia, low-cost (US\$17.50), low-literacy kit was designed and tested with the input of researchers, service providers, parents and state policymakers. Our research group at the Health Research for Action Center at the University of California, Berkeley, conducted pilot and longitudinal studies with parents and providers state-wide. In 2001, the kit was formally launched and distributed through the state's 58 counties according to local plans. It is now available to most new parents each year (about 500 000) and their service providers through prenatal programs, delivery hospitals, nurse home visits, telephone hotlines and other means. The evaluations showed that the kit significantly increased parents' knowledge and positive practices and was a valuable resource for providers. In 2004, First 5 decided to approve the kit as a long-term investment. Neuhauser and colleagues (2007a) report on the kit's development and evaluation. 
Bridging the 'Know-Do' Gap

The process to develop, implement and evaluate the kit and determine its longterm support posed many knowledge-brokering challenges. The next section describes strategies that facilitated this work among stakeholders.

\section{Six strategies to broker knowledge}

\section{Identify effective 'knowledge brokers' to lead and inspire stakeholders}

Rob Reiner, a well-known US film director and advocate for children, created the tobacco tax measure that established First 5, chaired the First 5 Commission, proposed the kit initiative and was the primary 'knowledge broker' for this effort. Reiner brought multiple strengths to the knowledge-broker role. He leveraged his worldwide celebrity, his credibility and experience on behalf of children's issues and his legislative savvy.

In the 1990s, Reiner established the international I Am Your Child foundation to highlight early childhood issues and strategies to address them. He helped organise a White House conference on early childhood issues hosted by President Bill Clinton and created television specials on this topic. He then established the Parents Action for Children initiative to provide education and support for the 65 million US parents. For each of these efforts, Reiner was successful in identifying advisors and supporters, including the small number of staff working at his non-profit organisations.

Reiner's brokering skills were equally effective in the legislative arena, where he led the passage of the proposition that authorised First 5. His approach was to organise his colleagues in media, early childhood and other sectors to gain state-wide support for the initiative. His media skills and recognition as being knowledgeable and passionate about early childhood issues were a powerful combination.

When he became chairman of First 5, Reiner used his reputation and charisma to develop good relationships with legislators, other policymakers, leaders from major service provider groups and researchers from universities and think tanks working on children's issues. He was able to interpret 'knowledge' and communicate it to stakeholders in a way that related to their own concerns and motivations. He also had the gift of communicating and 'transforming' knowledge about the initiative so that it inspired stakeholders' enthusiastic commitment. After he had secured the approval of the First 5 Commission to develop the kit and have an initial pilot test, he worked to engage and help local policymakers and service providers take on local leadership. Stakeholders from 
California's 58 counties were invited to attend state-level First 5 Commission meetings and to present and debate ideas about the program - an approach that sparked excitement and helped create effective plans.

\section{Use participatory approaches from the start}

From the outset, First 5 used highly participatory processes to design, test, revise and make decisions about the kit program. During the design phase, materials were reviewed and tested with parents, providers, health experts, representatives of advocacy groups and state policymakers. This process identified a number of initial errors that were corrected before the state-wide launch. Similarly, a participatory process was set up to design and refine kit distribution. First 5 established decentralised governance in each of the 58 counties that was designed to link policymakers, service providers and parents who would define local distribution plans.

As mentioned in strategy number one, researchers were engaged at the state level to advise on evidence-based information to include in the kit and to evaluate kit impacts. Counties were also encouraged to work with researchers to conduct local evaluations to help refine local plans. The close linkage of researchers, service providers and policymakers at state and local levels greatly helped share knowledge about the kit development, implementation and evaluation. It also helped stakeholders openly discuss and resolve issues about the kit. For example, when research results showed that the kit was more effective when given out before the baby's birth, many counties took that into consideration in their distribution plans. Likewise, service providers were encouraged to share issues and ideas at county, regional and state-wide meetings attended by First 5 policymakers. Stakeholders in remote areas, who could not attend these meetings, communicated their views through evaluators who interviewed them. Over the years, these participatory processes among stakeholders have become a strong 'feedback loop' to continuously identify problems and improvements.

\section{Identify and address stakeholder needs, commitments and barriers}

When the First 5 Commission initially approved the program, there were many concerns from stakeholders in local counties about whether the kit would be effective and whether systems could be set up to distribute it. For example, some researchers and service providers thought that, from their experience or interpretation of the literature, Spanish-speaking parents and those with limited literacy would not likely benefit from the kit. Policymakers and service providers worried about whether large-scale distributions would overwhelm 
systems and divert energy from other important activities. These concerns were discussed at the state First 5 meetings where stakeholders engaged in solving problems. As evidence from the pilot evaluation became available, researchers communicated it to other stakeholders. During the first six months of the pilot evaluation, results showed that Spanish speakers had excellent outcomes from using the kit, as did lower-educated parents. As principal investigator of the study, I presented findings at the state-wide meetings, had them put on the First 5 web site and made presentations in local counties to decision makers and key service providers. The evaluation was also designed to elicit the views of policymakers and key service providers in each of the 58 counties. The findings were 'brokered' to influence First 5 to make needed changes in the initiative - such as making the kits smaller so that they would be easier to store and distribute and developing kits in Asian languages.

\section{Emphasise effective communication}

As in all knowledge-brokering situations, communication played a central role in integrating stakeholder ideas for the kit program. As mentioned earlier, it helped that Reiner was a 'master communicator' and got this initiative off to a very positive and exciting start. Once the pilot initiative was under way and counties had to grapple with devising local plans and making the kit program successful, communication remained a critical knowledge-brokering strategy. For example, policymakers and service providers often have limited access to research results that they can understand and apply (Cheng et al. 2008; Clark and Kelly 2005). To overcome this problem, our research group worked with public relations firms to extract one and two-page summaries of key evaluation results and recommendations for specific ways findings could be used to improve the kit program. We also worked with a firm that specialised in creating engaging, easy to understand 'graphic reports' to produce a 15-page executive summary (in print and online) for researchers, policymakers and practitioners. In addition, we had the usual scientific technical reports and publications for researchers to review.

Oral presentations were also a challenge, given the diverse stakeholders. First 5 developed a system of having very brief presentations at its state-wide meetings with ample time for visiting stakeholders to comment. The content of the presentations was extracted into short written summaries that were handed out at the meetings and put online. Because the chairman of First 5 was a film director, short videos of the impact of the kit's use among parents and providers became one popular way to broker knowledge in a visual, emotional way. 


\section{Share and celebrate achievements and benefits to all stakeholders}

Stakeholders have different roles in designing, implementing and evaluating programs and sometimes this prevents their seeing the 'big-picture' value of their efforts. Policymakers approve programs, but might not grasp how activities work in the field and what they mean to beneficiaries. Researchers analyse program effects, but might not feel that they can take any credit for a program they did not implement. Practitioners are often caught up in the details of everyday implementation and might not understand the impact of their work.

Through its intensive emphasis on participatory processes, First 5 was effective in linking stakeholders in the work and helping them understand its impact. For example, when the kit pilot test proved successful, and First 5 decided to launch the kit program state-wide, there was a major event in Hollywood to which the media and stakeholders were invited. The event - hosted by Reiner - took place at a childcare centre that would distribute the kit and included celebrities, local service providers, policymakers and researchers. The event brought out the contributions of each of the stakeholder groups and their value to making the program a success. Periodically, other media events, including those on television and radio, have been held to celebrate milestones of the program. Program impacts are also shared at state and local meetings and on the Internet.

\section{Broker knowledge to extend programs}

Even if knowledge is brokered effectively and an initiative is successful, it is usually challenging to share that understanding with stakeholders in other settings. After the kit program showed good evidence of positive outcomes (Neuhauser et al. 2007a), there were a number of efforts to engage stakeholders beyond California. The approach began with policymakers in other states and in national and state advocacy organisations for children and parents. Reiner spoke with state governors and brought others involved in the Californian program to explain its operations and outcomes. I attended some of those meetings to present research findings. As in the First 5 program, there was strong emphasis on using communication that would inspire policymakers and other potential stakeholders.

To date, five other US states have begun or completed kit initiatives for all their new parents. Each of these efforts has involved sharing knowledge to help states develop an approach that is adapted to their own needs. For example, when the Virginia G. Piper Trust - a foundation in the state of Arizona-expressed interest in creating a kit program for that state's parents, First 5 stakeholders communicated with them by e-mail (and eventually in person) to describe 
approaches that had worked in California and problems to avoid. Designers of kit materials - including the publication group at our Health Research for Action Center-helped Arizona colleagues customise one resource for their kit and our research group provided data to Arizona decision makers about the outcomes in our state. Arizona adopted a participatory design process similar to that used in California: the foundation engaged service providers to work with other providers and with parents to draft and test kit materials. The foundation conducted a pilot evaluation of their kit leveraging survey design elements and instruments from the Californian study. Based on the positive outcomes in Arizona, the foundation decision makers have approved long-term funding for their kit program. They are now helping broker their experiences with colleagues in other states.

\section{Conclusions}

All too often, knowledge brokering is overlooked as a specific, critical factor in program design, implementation and evaluation (Bammer 2005; Canadian Health Services Research Foundation 2003; Clark and Kelly 2005; Gibson 2003; Greenhalgh et al. 2004; Kerner et al. 2005; Kiefer et al. 2005; Lomas 2000, 2007; van Kammen et al. 2005, 2006; WHO 2004). During the past two decades, theoretical guidance and empirical evidence have provided a good foundation to understand the value of knowledge brokering and the 'lessons learned' to do it well. What we have learned is that knowledge brokers need a range of specific skills and organisational structures to support their work. Initial results of such efforts are promising, especially when there is funding, dedicated efforts to train these 'boundary spanners' and established ways to link them with researchers, decision makers and practitioners.

Knowledge brokering is a revolutionary strategy that can advance the transition from historically weak approaches to powerful ways of creating synergy among researchers, decision makers and practitioners to benefit society. One of the most effective ways to leverage knowledge brokering is to promote interventions that support parents of young children. In the case study presented here, the six knowledge-brokering skills were key in designing, implementing, evaluating and revising a large-scale parenting program that has positively impacted millions of families. 


\section{References}

Abrams, D. B. 2006, 'Applying transdisciplinary research strategies to understanding and eliminating health disparities', Health Education and Behavior, vol. 33, no. 4, pp. 515-31.

Bammer, G. 2005, 'Integration and implementation sciences: building a new specialization', Ecology and Society, vol. 10, no. 2, viewed 19 March 2007, $<$ http://www.ecologyandsociety.org/vol10/iss2/art6/>

Bammer, G. and Smithson, M. (eds) 2008, Uncertainty and Risk: Multidisciplinary perspectives, Earthscan, London and Sterling, Va.

Best, A., Hiatt, R. A. and Norman, C. D. 2007, 'Knowledge integration: conceptualizing communications in cancer control systems', Patient Education and Counseling, vol. 71, no. 3, pp. 319-27.

Bielak, A. T., Campbell, A., Pope, S., Schaefer, K. and Shaxson, L. 2008, 'From science communication to knowledge brokering: the shift from "science push" to "policy pull"', in D. Cheng, M. Claessens, T. Gascoigne, J. Metcalfe, B. Schiele and S. Shi (eds), Communicating Science in Social Contexts, Springer Netherlands, The Netherlands.

Canadian Health Services Research Foundation 2003, The Theory and Practice of Knowledge Brokering in Canada's Health System, Canadian Health Services Research Foundation, Ottawa, viewed 3 May 2010, <www.chsrf.ca/ brokering/pdf/Theory_and_Practice_e.pdf>

Case, A., Fertig, A. and Paxson, C. 2005, 'The lasting impact of childhood health and circumstance', Journal of Health Economics, vol. 24, pp. 365-89.

Cheng, D., Claessens, M., Gascoigne, T., Metcalfe, J., Schiele, B. and Shi, S. (eds) 2008, Communicating Science in Social Contexts, Springer Netherlands, The Netherlands.

Clark, G. and Kelly, E. 2005, New Directions for Knowledge Transfer and Knowledge Brokerage in Scotland, Office of the Chief Researcher, Scottish Executive, Edinburgh, viewed 3 May 2010, <www.scotland.gov.uk/ Resource/Doc/69582/0018002.pdf>

Ferlie, E., Fitzgerald, L. and Wood, M. 2000, 'Getting evidence into clinical practice: an organizational behaviour perspective', Journal of Health Service Research Policy, vol. 5, pp. 96-102. 
Bridging the 'Know-Do' Gap

Furler, L. 2008, 'Smoke and mirrors: managing uncertainty in the public health sector', in G. Bammer and M. Smithson (eds), Uncertainty and Risk: Multidisciplinary perspectives, Earthscan, London and Sterling, Va, pp. 18393.

Gibson, B. 2003, From transfer to transformation: rethinking the relationship between research and policy, Dissertation, National Centre for Epidemiology and Population Health, The Australian National University, Canberra, viewed 3 May 2010, <http://thesis.anu.edu.au/public/adt-ANU20040528.165124/ index.html>

Gomby, D. S., Larner, M. B., Stevenson, C. S., Lewit, E. M. and Behrman, R. E. 1995, 'Long-term outcomes of early childhood programs: analysis and recommendations', Future Child, vol. 5, pp. 6-24.

Green, L. W. 2001, 'From research to best practices in other settings and populations', American Journal of Health Behavior, vol. 25, pp. 165-78.

Green, L. W. and Glasgow, R. E. 2006, 'Evaluating the relevance, generalization, and applicability of research: issues in external validation and translation methodology', Evaluation and the Health Professions, vol. 29, no. 1, pp. 12653.

Greenhalgh, T., Robert, G., Macfarlane, F., Bate, P. and Kyriakidou, O. 2004, 'Diffusion of innovations in service organizations: systematic review and recommendations', Milbank Quarterly, vol. 82, pp. 581-629.

Heckman, J. 2000, Policies to Foster Human Capital, Irving B. Harris Graduate School of Public Policy Studies, University of Chicago, Ill.

Hutchings, A., Raine, R., Sanderson, S. and Black, N. 2006, 'A comparison of formal consensus methods used for developing clinical guidelines', Journal of Health Service Research Policy, vol. 11, pp. 218-24.

Innvaer, S., Vist, G., Trommald, M. and Oxman, A. 2002, 'Health policy-makers' perceptions of their use of evidence: a systematic review', Journal of Health Service Research Policy, vol. 7, pp. 239-44.

Israel, B., Schulz, A., Parker, E. and Becker, A. 1998, 'Review of communitybased research: assessing partnership approaches to improve health', Annual Review of Public Health, vol. 19, pp. 173-202.

Karoly, L. A., Greenwood, P. W., Everingham, S. S., Hoube, J., Kilburn, M. R., Rydell, C. P., Sanders, M. and Chiesa J. 1998, Investing in our children: what we know and don't know about the costs and benefits of early childhood interventions, Report no. MR-898-TCWF, RAND, Santa Monica, Calif. 
Kerner, J., Rimer, B. and Emmons, K. 2005, 'Dissemination research and research dissemination: how can we close the gap?', Health Psychology, 24, pp. 443-6.

Kiefer, L., Frank, J., Di Ruggerio, E., Dobbins, M., Manuel, D., Gully, P. and Mowat, D. 2005, 'Fostering evidence-based decision-making in Canada: examining the need for a Canadian population and public health evidence centre and research network', Canadian Journal of Public Health, vol. 96, pp. Il-19.

King, L., Hawe, P. and Wise, M. 1998, 'Making dissemination a two-way process', Health Promotion International, vol. 13, no. 3, pp. 237-44.

Lavis, J. N., Robertson, D., Woodside, J. M., McLeod, C. B. and Abelson, J. 2003, 'Knowledge transfer study group. How can research organizations more effectively transfer research knowledge to decision makers?', Milbank Quarterly, vol. 81, pp. 221-48.

Leischow, S. J., Best, A., Trochim, W. M., Clark, P. I., Gallagher, R. S., Marcus, S. E. and Matthews, E. 2008, 'Systems thinking to improve the public's health', American Journal of Preventive Medicine, vol. 35, no. 2S, pp. S196-203.

Lenaway, D., Halverson, P., Sotnikov, S., Tilson, H., Corso, L. and Millington, W. 2006, 'Public health systems research: setting a national agenda', American Journal of Public Health, vol. 96, no. 3, pp. 410-13.

License, K. 2004, 'Promoting and protecting the health of children and young people', Child Care Health Development, vol. 30, pp. 623-35.

Lomas, J. 2000, 'Using "linkage and exchange" to move research into policy at a Canadian foundation', Health Affairs, vol. 19, pp. 236-40.

Lomas, J. 2007, 'The in-between world of knowledge brokering', British Medical Journal, vol. 334, pp. 129-32.

McCain, M. N. and Mustard, J. F. 2002, The Early Years Study. Three years later, Publications Ontario, Toronto.

Minkler, M. and Wallerstein, N. (eds) 2003, Community Based Participatory Research in Health, Jossey-Bass, San Francisco.

National Institute of Child Health and Human Development (NICHD) Early Child Care Research Network 2000, 'The relation of child care to cognitive and language development', Child Development, vol. 71, pp. 960-80.

Neuhauser, L. and Kreps, G. 2003, 'Rethinking communication in the e-health era', Journal of Health Psychology, vol. 8, no. 1, pp. 7-23. 
Neuhauser, L., Constantine, W. L., Constantine, N. A., Sokal-Gutierrez, K., Obarski, S. K., Clayton, L., Desai, M., Sumner, G. and Syme, S. L. 2007a, 'Promoting prenatal and early childhood health: evaluation of a statewide materials-based intervention for parents', American Journal of Public Health, vol. 97, no. 10, pp. 813-19.

Neuhauser, L., Richardson, D., MacKenzie S. and Minkler, M. 2007b, 'Transdisciplinary and translational doctoral education in public health: issues, trends and innovative models', Journal of Research Practice, vol. 3, no. 2, <http://jrp.icaap.org/index.php/jrp/article/view/103/97>

Rogers, E. 1982, Diffusion of Innovations, Third edn, Free Press, New York.

Shonkoff, J. P. and Phillips, D. A. (eds) 2000, From Neurons to Neighborhoods: The science of early child development, National Academy Press, Washington, DC.

Shore, R. 1997, Rethinking the Brain: New insights into early development, Families and Work Institute, New York.

Simpson, L. 2004, 'Lost in translation? Reflections on the role of research in improving health care for children', Health Affairs, vol. 23, pp. 125-30.

Stokols, D. 2000, 'Social ecology and behavioral medicine: implications for training, practice, and policy', Behavioral Medicine, vol. 26, pp. 129-38.

Stokols, D. 2006, 'Toward a science of transdisciplinary research', American Journal of Community Psychology, vol. 38, pp. 63-77.

Stokols, D., Hall, K. L., Taylor, B. K., Moser, R. P. and Syme, S. L. (eds) 2008, 'The science team science: assessing the value of transdisciplinary research', American Journal of Preventive Medicine, vol. 35, no. 2S (August).

Sussman, S., Valente, T. W., Rohrbach, L. A., Skara, S. and Pentz M. A. 2006, 'Translation in the health professions: converting science into action', Evaluation and the Health Professions, vol. 29, no. 1, pp. 7-32.

Tsui, L. 2006, A Handbook on Knowledge Sharing: Strategies and recommendations for researchers, policymakers, and service providers, Community-University Partnership for the Study of Children, Youth, and Families, Alberta.

van Kammen, J., Jansen, K. and Hoeksema, J. 2005, 'Knowledge brokering: a business model', Italian Journal of Public Health, vol. 2, p. 120.

van Kammen, J., de Savigny, D. and Sewankambo, H. 2006, ‘Using knowledge brokering to promote evidence-based policy-making: the need for support structures', Bulletin of the World Health Organization, vol. 84, pp. 608-12. 
Walshe, K. and Rundall, T. G. 2001, 'Evidence-based management: from theory to practice in health care', Milbank Quarterly, vol. 79, pp. 429-57.

World Health Organisation (WHO) 2004, World Report on Knowledge for Better Health, World Health Organisation, Geneva, <www.who.int/rpc/wr2004>

Zervignon-Hakes, A. M. 1995, 'Translating research findings into large-scale public programs and policy', Future Child, vol. 5, no. 3. 